\title{
Trial Visits Supplemental Qualifiers Dataset
}

National Cancer Institute

\section{Source}

National Cancer Institute. Trial Visits Supplemental Qualifiers Dataset. NCI Thesaurus. Code C147265.

A dataset containing supplemental information, specifically non-standard variables, to parent records in the trial visits domain. 